\title{
As(III) Removal from Aqueous Solution by Calcium Titanate Nanoparticles Prepared by the Sol Gel Method
}

\author{
Rocío Tamayo ${ }^{1}$, Rodrigo Espinoza-González ${ }^{1, *}$, Francisco Gracia ${ }^{1}$, \\ Ubirajara Pereira Rodrigues-Filho ${ }^{2}$, Marcos Flores ${ }^{3}$ and Elisban Sacari ${ }^{4}[\mathbb{C}$ \\ 1 LabMAM, Depto. de Ingeniería Química Biotecnología y Materiales, FCFM, Universidad de Chile, Av. \\ Beauchef 851, Santiago 8370456, Chile; rocio.tamayo@ing.uchile.cl (R.T.); fgracia@ing.uchile.cl (F.G.) \\ 2 Grupo de Química de Materiais Híbridos e Hinorgânicos, Instituto de Química de Sao Carlos, \\ Universidade de São Paulo, 13563-120 São Carlos, SP, Brazil; ubirajara@usp.br \\ 3 Laboratorio de Superficies, Depto. de Física, FCFM, Universidad de Chile, Av. Blanco Encalada 2008, \\ Santiago 8370449, Chile; mflorescarra@ing.uchile.cl \\ 4 Laboratorio de Nanomateriales, Facultad de Ingeniería, Universidad Nacional Jorge Basadre Grohmann, \\ Av. Miraflores s/n, Tacna 23003, Peru; esacaris@unjbg.edu.pe \\ * Correspondence: roespino@ing.uchile.cl; Tel.: +562-2978-4239
}

Received: 17 April 2019; Accepted: 8 May 2019; Published: 13 May 2019

\begin{abstract}
Arsenic (As) contamination of water is a serious problem in developing countries. In water streams, arsenic can be as $\mathrm{As}(\mathrm{V})$ and $\mathrm{As}(\mathrm{III})$, the latter being the most toxic species. In this work, an innovative adsorbent based on $\mathrm{CaTiO}_{3}$ nanoparticles (CTO) was prepared by the sol-gel technique for the removal of As(III) from aqueous solution. X-ray diffraction of the CTO nanoparticles powders confirmed the CTO phase. Transmission electron microscopy observations indicated an average particle size of $27 \mathrm{~nm}$, while energy dispersive $X$-ray spectroscopy analysis showed the presence of $\mathrm{Ca}, \mathrm{Ti}$, and $\mathrm{O}$ in the expected stoichiometric amounts. The surface specific area measured by Brunauer, Emmett, and Teller (BET) isotherm was $43.9 \mathrm{~m}^{2} / \mathrm{g}$, whereas the isoelectric point determined by Zeta Potential measurements was at $\mathrm{pH}$ 3.5. Batch adsorption experiments were used to study the effect of $\mathrm{pH}$ on the equilibrium adsorption of $\mathrm{As}(\mathrm{III})$, using an arsenite solution with $15 \mathrm{mg} / \mathrm{L}$ as initial concentration. The highest removal was achieved at $\mathrm{pH} 3$, reaching an efficiency of up to $73 \%$, determined by X-ray fluorescence from the residual As(III) in the solution. Time dependent adsorption experiments at different $\mathrm{pHs}$ exhibited a pseudo-second order kinetics with an equilibrium adsorption capacity of $11.12 \mathrm{mg} / \mathrm{g}$ at $\mathrm{pH} 3$. Moreover, CTO nanoparticles were regenerated and evaluated for four cycles, decreasing their arsenic removal efficiency by $10 \%$ without affecting their chemical structure. X-ray photoelectron spectroscopy analysis of the CTO surface after removal experiments, showed that arsenic was present as As(III) and partially oxidized to $\mathrm{As}(\mathrm{V})$.
\end{abstract}

Keywords: arsenic adsorption; sol-gel technique; calcium titanate; nanoparticles; adsorption kinetic

\section{Introduction}

Water is one of the fundamental factors for the development of humanity. The contamination of water sources with arsenic (As) is a serious worldwide problem. It is estimated that between 60 and 100 million people in the world are exposed to the presence of As in drinking water, in concentrations harmful to health. It has been reported that at least 21 countries have high concentrations of As in their groundwater [1,2]. The most affected areas in the world are South-East Asia, in countries such as Bangladesh, India, Nepal, Taiwan and Vietnam, where concentrations of As that exceed $1 \mathrm{mg} / \mathrm{L}$ have 
been reported [3]. The World Health Organization (WHO) sets as maximum permissible limit $10 \mu \mathrm{g} / \mathrm{L}$ of As in drinking water [4].

It is known that in Latin America that the problem of As pollution is present in more than 14 countries, such as Argentina, Bolivia, Brazil, Chile, Colombia, Cuba, Ecuador, El Salvador, Guatemala, Honduras, Mexico, Nicaragua, Peru, and Uruguay [5]. Arriaza et al. carried out studies on samples of mummies belonging to the Chinchorro culture, who lived between the cities of Ilo in Southern Peru and Antofagasta in Chile 7000 years ago, reporting that they suffered from arsenic, which could be caused by ingestion of food and water contaminated with As [6]. Waters contaminated with As are a hazard to humans, and chronic exposure to contaminated water intake causes different diseases. Some studies indicate that As could be associated with skin cancer and internal organs [7].

In water streams, arsenic chemical species are arsenate $(\mathrm{As}(\mathrm{V}))$ and arsenite (As(III)) [8]. As(III) is the major species under reducing environmental conditions, as well as the most toxic species $[9,10]$. $\mathrm{As}(\mathrm{V})$ is negatively charged in the $\mathrm{pH}$ range of $2.5-12$, while As(III) is negatively charged above $\mathrm{pH} 9$ [11].Therefore, arsenite or arsenate sorption from aqueous solution is strongly dependent on $\mathrm{pH}$ and surface stability constants whenever inner-sphere complex formation comes into play [12,13].

The removal of As has been improved with the advances of technology. The most used processes for removal of As are coagulation, oxidation, precipitation, adsorption with different materials, resins for ion exchange, and membrane technology as conventional methods. At large scale the most employed are the coagulation methods with $\mathrm{Al}$ and Fe salts although combined with other processes as filtration and oxidation [2]. Hu et al. established an optimal $\mathrm{pH}$ between 5 and 7 in the study of the effects of aluminum speciation during the removal of $\mathrm{As}(\mathrm{V})$ in coagulation processes [14]. Lacasa et al. [15] reported the removal of $10 \mu \mathrm{g} / \mathrm{dm}^{3}$ of As using an electrocoagulation process with electrodes of $\mathrm{Fe}$ and $\mathrm{Al}$; while Mohora et al. [16] obtained 93\% removal of As using a continuous electrocoagulation/flocculation process.

The adsorption of $\mathrm{As}(\mathrm{III})$ by nanocomposites of $\mathrm{Cu}$-chitosan/nano- $\mathrm{Al}_{2} \mathrm{O}_{3}$ has also been studied; and the high adsorption capacity and high initial velocity of this nanocomposite were demonstrated [17]. Hlavay et al. studied the superficial properties of alumina covered with $\mathrm{Fe}(\mathrm{OH})_{2}$ for which the adsorption capacity is a function of the $\mathrm{pH}$. They obtained a selective and efficient adsorbent for arsenite and arsenate ions [18]. Activated carbon is a widely used material in adsorption of arsenic. Vitela et al. [19] investigated arsenic adsorption by activated carbon modified with Fe nanoparticles and reached a maximum capacity of $\mathrm{As}(\mathrm{V})$ of $1.25 \mathrm{mg} / \mathrm{g}$, that decreases by $32 \%$ when the $\mathrm{pH}$ increases from 6 to 8. Mesoporous activated carbon for the adsorption of $\mathrm{As}(\mathrm{III}) / \mathrm{As}(\mathrm{V})$ has also been studied reaching a maximum removal of 1.491 and $1.760 \mathrm{mg} / \mathrm{g}$ [20]. Complex absorbents such as Fe-Mn-Ce ternary oxide-biochar composites have been recently reported by Liu et al. [21] for the removal of As(III); which exhibited a maximum sorption capacity of $8.47 \mathrm{mg} / \mathrm{g}$ and the greatest adsorption at $\mathrm{pH} 3$. Similarly, good adsorption results have been obtained for metal-organic framework-graphene oxide (MOF-GO) nanocomposites. Chowdhury et al. [22] showed high adsorption capacity of MOF-GO materials but with the maximum capacity at $\mathrm{pH} 11$.

As is mainly found as compounds of $\mathrm{As}(\mathrm{V})$ and $\mathrm{As}(\mathrm{III})$. The former is present in surface waters and the second in groundwater. It is known that As(III) is more toxic and difficult to remove from water than $\mathrm{As}(\mathrm{V})$, so a strategy for removal is first to oxidize the $\mathrm{As}(\mathrm{III})$ to $\mathrm{As}(\mathrm{V})$ to achieve a more effective removal [9]. This implies that the treatment methods used today have several stages that lead to higher costs.

Due to the above, there is a motivation to search for new alternatives for the removal of As, that allow the treatment of removal in a single stage. This work proposes the use of nanoparticles of perovskite type $\mathrm{CaTiO}_{3}$ (CTO) obtained by the sol-gel methods, for the adsorbent function of $\mathrm{As}(\mathrm{III})$, which has been little studied with this type of perovskite. In addition, it will allow us to look for the generation of a new system that facilitates the removal of As (III) using a simple ceramic prepared from earth abundant materials. 


\section{Materials and Methods}

\subsection{Synthesis of $\mathrm{CaTiO}_{3}$ Nanopowder}

Pure $\mathrm{CaTiO}_{3}$ (CTO) perovskite nanoparticles were prepared by the sol-gel method. In this synthesis, titanium (IV) isopropoxide $\mathrm{Ti}\left(\mathrm{OC}_{3} \mathrm{H}_{7}\right)_{4}(97 \%$ Sigma-Aldrich, St. Louis, MO, USA ), calcium (II) nitrate tetrahydrate $\mathrm{Ca}\left(\mathrm{NO}_{3}\right)_{2} \cdot 4 \mathrm{H}_{2} \mathrm{O}$ (99\% Sigma-Aldrich, St. Louis, MO, USA), 2-propanol (EMSUREß), Merk, Darmstadt, Germany), and citric acid monohydrate $\mathrm{C}_{6} \mathrm{H}_{8} \mathrm{O}_{7} \cdot \mathrm{H}_{2} \mathrm{O}$ ( $\geq 99 \%$ Sigma-Aldrich, St. Louis, MO, USA), were used as starting materials. All the chemicals were of analytical grade and no further purification was performed. The synthesis steps are the following (Figure 1): a) $\mathrm{Ti}\left(\mathrm{OC}_{3} \mathrm{H}_{7}\right)_{4}$, $\mathrm{Ca}\left(\mathrm{NO}_{3}\right)_{2} \cdot 4 \mathrm{H}_{2} \mathrm{O}$ and citric acid were weighed accurately according to the stoichiometric composition, and dissolved separately in 2-propanol, under vigorous stirring for $30 \mathrm{~min}$; b) once the solution of $\mathrm{Ca}\left(\mathrm{NO}_{3}\right)_{2} \cdot 4 \mathrm{H}_{2} \mathrm{O}$ was added drop by drop to the solution of $\left.\mathrm{Ti}\left(\mathrm{OC}_{3} \mathrm{H}_{7}\right)_{4}\right)$, the solution of citric acid was likewise added drop by drop to obtain a CTO precursor solution; c) this last solution was stirred vigorously for $30 \mathrm{~min}$ at room temperature while deionized water was slowly added until the gel was formed; d) then, the gel was dried at $50{ }^{\circ} \mathrm{C}$ for $96 \mathrm{~h}$. The resultant powder (xerogel) was ground in an agate mortar for $5 \mathrm{~min}$ and finally calcined at $600^{\circ} \mathrm{C}$ over $1 \mathrm{~h}$ in air to obtain CTO powder.

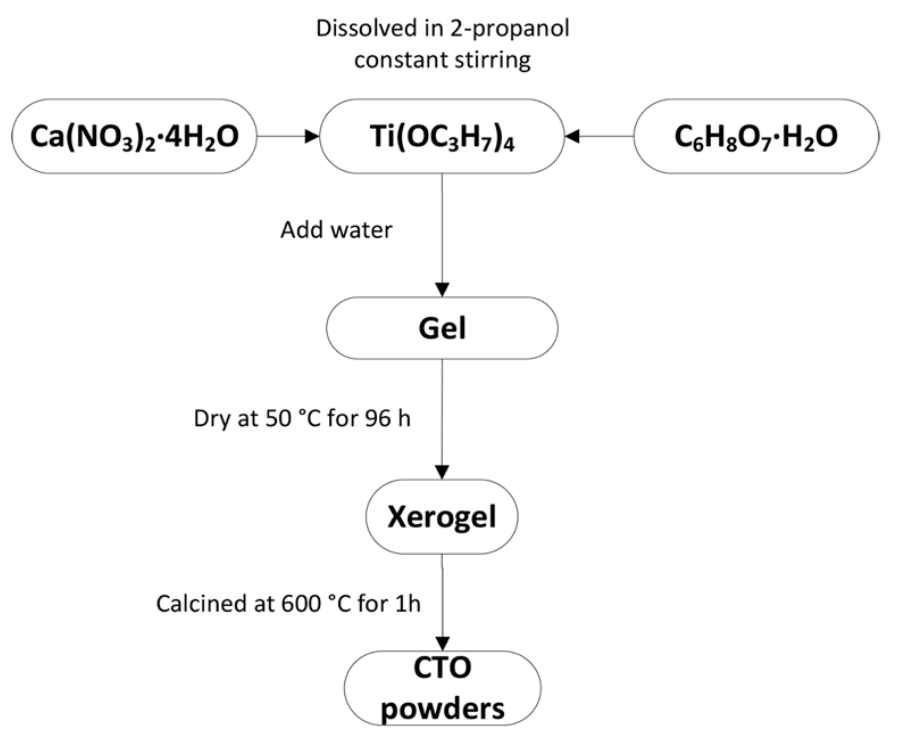

Figure 1. Flowchart for $\mathrm{CaTiO}_{3}$ nanoparticles (CTO) preparation procedure.

\subsection{Characterization}

Thermal properties of the dry gel precursor were determined using a thermogravimetric analyzer TA instrument, model TGA Q-50 and differential scanning calorimeter DSC Q-20 (TA instrument, New Castle, DE, USA), under nitrogen atmosphere and at heating rate of $5{ }^{\circ} \mathrm{C} / \mathrm{min}$. The obtained powders were characterized by X-ray diffraction (XRD) in a D8 Bruker (Billerica, MA, USA) diffractometer using $\mathrm{CuK} \alpha$ radiation $(\lambda=1.5418 \AA)$. The morphology and microstructure of the samples were studied by transmission electron microscopy (TEM) in a FEI Tecnai F20 FEG-S/TEM (Eindhoven, The Netherlands) microscope operated at $200 \mathrm{kV}$, with EDAX detector for energy dispersive X-ray spectroscopy (EDX). The specific surface area of the powders was measured by nitrogen adsorption isotherm using the Brunauer, Emmett and Teller (BET) equation in a Micromeritics ASAP 2010 (Norcross, GA, USA) apparatus at $-196^{\circ} \mathrm{C}$. The point of zero charge $\left(\mathrm{pH}_{\mathrm{pzc}}\right)$ was measured employing a ZSNano Zetasizer instrument (ZEN 3600, Malvern, Worcestershire, UK). A solution of $\mathrm{KCl}$ with a concentration of $0.003 \mathrm{~mol} / \mathrm{L}$ was prepared, in which the CTO sample was added; to this solution of $\mathrm{KCl}+\mathrm{CTO}, \mathrm{HCl}$ and $\mathrm{KOH}$ were added to vary the $\mathrm{pH}$. 


\subsection{Batch Adsorption Experiments}

Different sets of $100 \mathrm{~mL}$ solutions containing As(III) were prepared using sodium arsenite $\left(\mathrm{NaAsO}_{2}\right)$ with an initial concentration of $15 \mathrm{mg} \mathrm{L}^{-1}$ and different $\mathrm{pHs}$ (1 to 11), and $100 \mathrm{mg}$ CTO was added. This mixture was stirred and $2 \mathrm{~mL}$ aliquots were taken at 6, 12, 18, 24, 30, 40, 60, and $80 \mathrm{~min}$. The total As concentration in the aliquots was determined by using X-ray fluorescence analysis using a benchmark MiniPal4 (PANalytical, Almedo, The Netherlands) spectrometer in energy dispersive mode. The semi-quantitative determination of arsenic removal was performed using the standard less analysis package Omnian (PANalytical). All the measurements were acquired after a total measurement time of $840 \mathrm{~s}$ and were done in triplicate. A similar process was employed to evaluate the potential dissolution of $\mathrm{CTO}$ under acidic conditions at $\mathrm{pH} 1,2$, and 3 . In this case, the aliquots were centrifuged to separate solids and the residual liquid was analyzed by XRF.

On the other hand, the final solutions after $80 \mathrm{~min}$. of the adsorption experiments were centrifuged of at $5000 \mathrm{rpm}$ on $10 \mathrm{~min}$ to recover the solids of CTO nanoparticles. The solids were dried at $115^{\circ} \mathrm{C}$ over $3 \mathrm{~h}$ to study their superficial chemical composition after adsorption, which was analyzed by means of the X-ray photoelectron spectroscopy technique (XPS). This was performed using an XPS-Auger PerkinElmer spectrometer model PHI 1257 (PerkinElmer Corporation, Eden Prairie, MN, USA), with an $\mathrm{X}$-ray source of $\mathrm{K} \alpha$ radiation from an $\mathrm{Al}(\mathrm{h} v=1486.6 \mathrm{eV})$ anode. The measurements were performed at $200 \mathrm{~W}$ and take-off angle of $45^{\circ}$. The binding energies were calibrated relative to $\mathrm{C} 1 \mathrm{~s}(284.6 \mathrm{eV})$ from adventitious contamination on the sample surface.

\subsection{Ion Effect and Adsorption/Desorption Cycles}

Natural water streams contain several ions, which may affect the adsorption process. Cornejo et al. [23] reported the removal of arsenic from natural waters by zero-valent iron assisted by solar radiation. They characterized the water contaminants of the Camarones River (Atacama Desert in northern Chile), in which the arsenic concentration ranges between 1000 and $1300 \mathrm{mg} \mathrm{L}^{-1}$. Besides arsenic, the analysis performed by them found chloride $\left(\mathrm{Cl}^{-}\right)$, sulfates $\left(\mathrm{SO}_{4}^{2-}\right)$, and carbonates $\left(\mathrm{CO}_{3}^{2-}\right)$, with maximum concentrations of 670,235 , and $420 \mathrm{mg} \mathrm{L}^{-1}$, respectively. Thus, the influence of these three co-existing anions on arsenic adsorption was studied, also considering $\mathrm{NO}_{3}^{-}$as a common ion present in natural waters [24]. The tests were conducted using the coexisting amounts of anions in natural waters using the batch experiment methodology described in Section 2.3. To prepare the solutions, different sodium salts $\left(\mathrm{NaNO}_{3}, \mathrm{NaCl}, \mathrm{NaCO}_{3}\right.$, and $\mathrm{NaSO}_{4}$, over $99 \%$ pure, Merck, Darmstadt, Germany) were used. Each one was added in concentrations of 100,250 , and $500 \mathrm{mg} \mathrm{L}^{-1}$ to solutions of As (III) with $15 \mathrm{mg} \mathrm{L}^{-1}$ initial concentration and $1 \mathrm{~g} \mathrm{~L}^{-1}$ of CTO at $\mathrm{pH} 3$.

Additionally, adsorption/desorption cycles were performed using the same batch adsorption conditions. Desorption was in a solution of $\mathrm{NaOH} 1 \mathrm{M}$ for $1 \mathrm{~h}$ at $300 \mathrm{rpm}$, afterwards a $2 \mathrm{~mL}$ aliquot was taken to measure the total As release from the CTO surface. Then, the solution was centrifuged and washed with deionized water several times until neutral $\mathrm{pH}$ was reached. The residual solid was dried at $115^{\circ} \mathrm{C}$ for $3 \mathrm{~h}$ and reused for the adsorption experiments up to four times. In this experiment, the total As measurement was carried out in an atomic adsorption equipment with graphite furnace brand Shimadzu model AA-6300. XRD analysis of CTO powders was also performed before and after the tests in an X-ray diffractometer PANalitycal model AERIS (Malvern Panalytical Ltda., Almedo, The Netherlands) operated at $40 \mathrm{Kv}$ and $15 \mathrm{~mA}$.

\section{Results}

\subsection{Characterization of CTO Nanopowders}

Figure 2 shows the TG-DSC curves of the dried precursor (xerogel). It can be seen that in the range 30 to $200{ }^{\circ} \mathrm{C}$ there is a weight loss of $42 \%$ in the TG curve (black line), which is attributed to the removal of water adsorbed on the powders surface [25]. Up to $500{ }^{\circ} \mathrm{C}$ there is an additional mass loss of $30 \%$ that would be related to the decomposition of citric acid mainly in the form of $\mathrm{CO}_{2}$ and 
$\mathrm{NH}_{3}$ [26]. The DSC curve (blue line) shows two endothermic peaks between 100 and $200{ }^{\circ} \mathrm{C}$ assigned to the elimination of alcohol and water [27]. Between 500 and $600{ }^{\circ} \mathrm{C}$ an exothermic peak appears attributed to the combustion of organic waste and to the crystallization process [28,29]. Based on the TG-DSC analysis, a calcination temperature of $600{ }^{\circ} \mathrm{C}$ was chosen as the optimum temperature for the formation of $\mathrm{CaTiO}_{3}$.

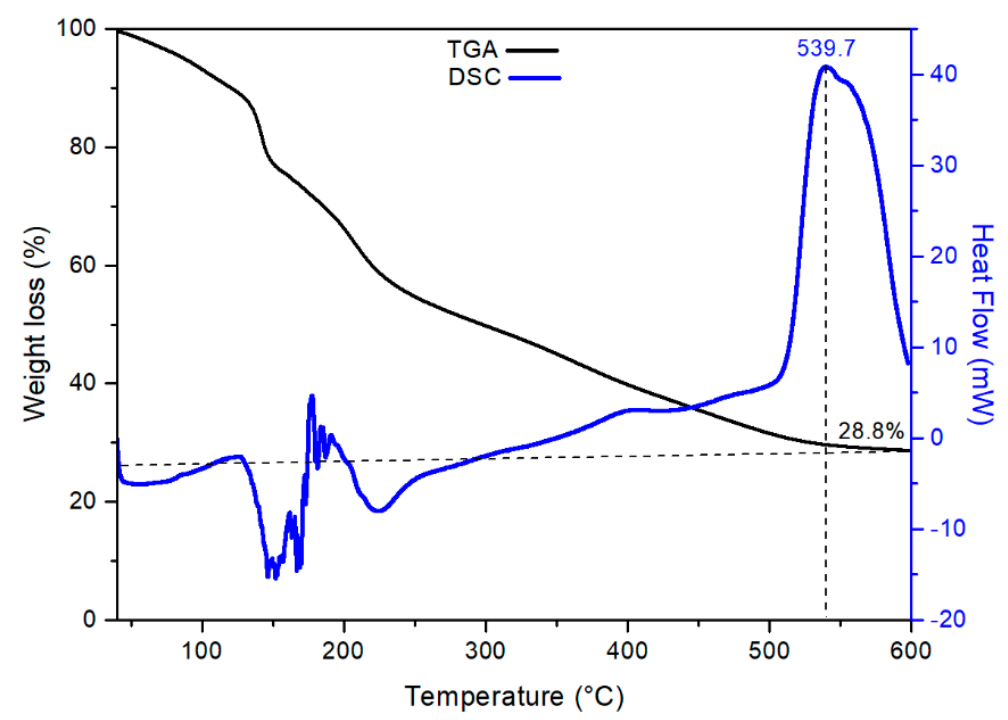

Figure 2. TG-DSC curves of dry gel (xerogel) powder precursor of CTO.

Figure 3 displays the XRD pattern of calcined powders, which shows the formation of the single-phase CTO in the powders after the calcination step. The observed peaks in the pattern can be indexed as CTO according to the JCPDS card $\mathrm{N}^{\circ} 78-1013$ that corresponds to the characteristic orthorhombic phase with Pbnm space group.

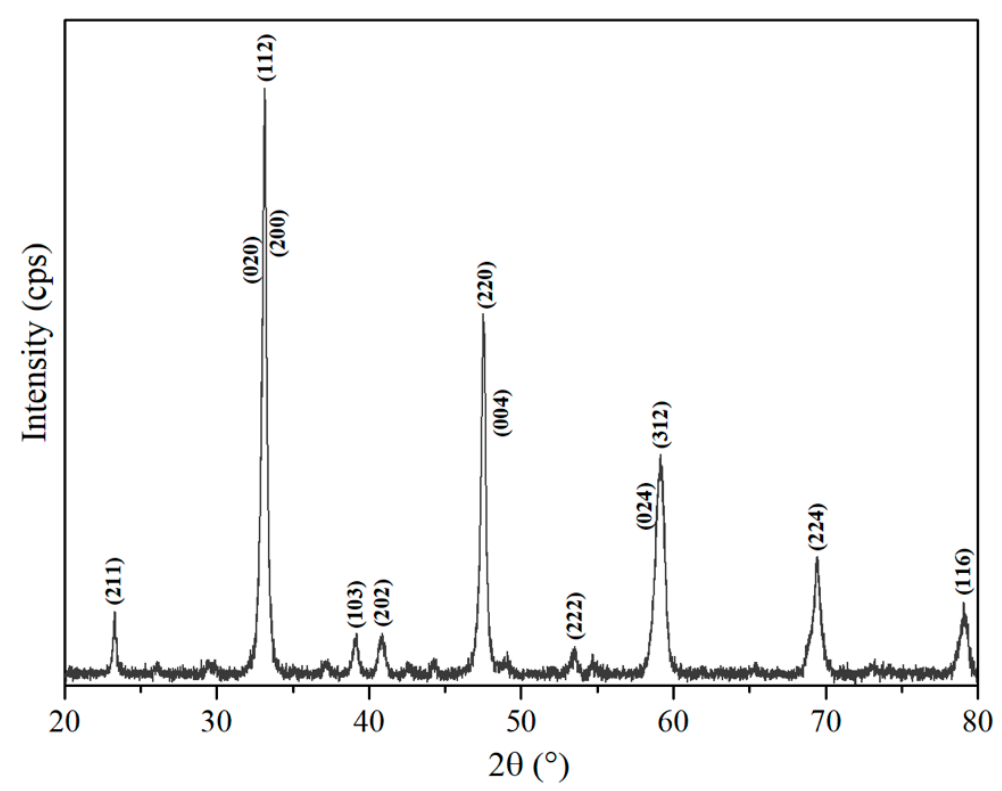

Figure 3. XRD pattern of CTO calcined powders.

The morphology and microstructure of calcined CTO powders were analyzed by TEM (Figure 4). The CTO particles exhibited an irregular shape, which size ranges between 10 and $40 \mathrm{~nm}$, and an average diameter of $27 \mathrm{~nm}$. The inset plot of Figure 4 displays the histogram of the particles size 
distribution, which follows a lognormal size distribution. Elemental analysis of the CTO nanoparticles showed the presence of $\mathrm{Ca}$, Ti, and $\mathrm{O}$ in the expected stoichiometric amounts (not shown here).

The surface specific area of CTO powders obtained by BET isotherm was $43.9 \pm 0.1 \mathrm{~m}^{2} / \mathrm{g}$, that is higher than the $1.6 \mathrm{~m}^{2} / \mathrm{g}$ of commercially CTO used by Jia et al. [30]. Zhuang et al. [31] reported surface areas between 28.34 and $108.14 \mathrm{~m}^{2} / \mathrm{g}$ for СТO prepared by the hydrothermal method using different titanium precursors $\left(\mathrm{TiCl}_{4}, \mathrm{Ti}\left(\mathrm{OC}_{3} \mathrm{H}_{7}\right)_{4}\right.$ and $\left.\mathrm{Ti}\left(\mathrm{OC}_{4} \mathrm{H}_{9}\right)_{4}\right)$. Their nanoparticles exhibited different morphologies with varied particle sizes up to the nanometric range.

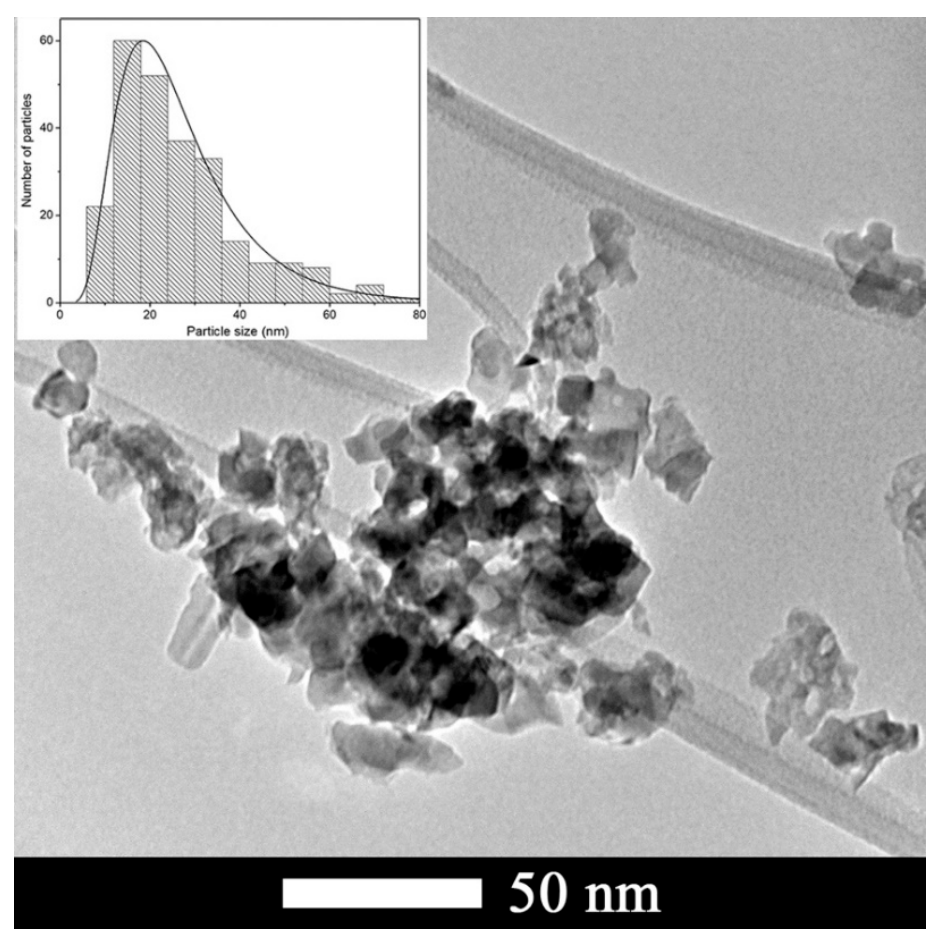

Figure 4. TEM image of CTO nanoparticles. Inset: Particle size distribution of 253 nanoparticles obtained from 26 TEM different images.

The Zeta Potential measurements as a function of suspended CTO were performed to determine the zero charge point or also known as the isoelectric point (IEP). This is an important parameter for the adsorption processes of any ionic adsorbate from water, since $\mathrm{pH}$ affects speciation of the ionic species as well as the characteristics of the absorbents surface. Based on Figure 5, the $\mathrm{pH}$ dependence of the zeta potential curve allows determination of the zero-charge point for $\mathrm{CTO}$ at $\mathrm{pH} 3.5$. This value is closed to that obtained by Coreño et al. [32] where the CTO (commercial) reaches the zero-load point at $\mathrm{pH} 3$. 


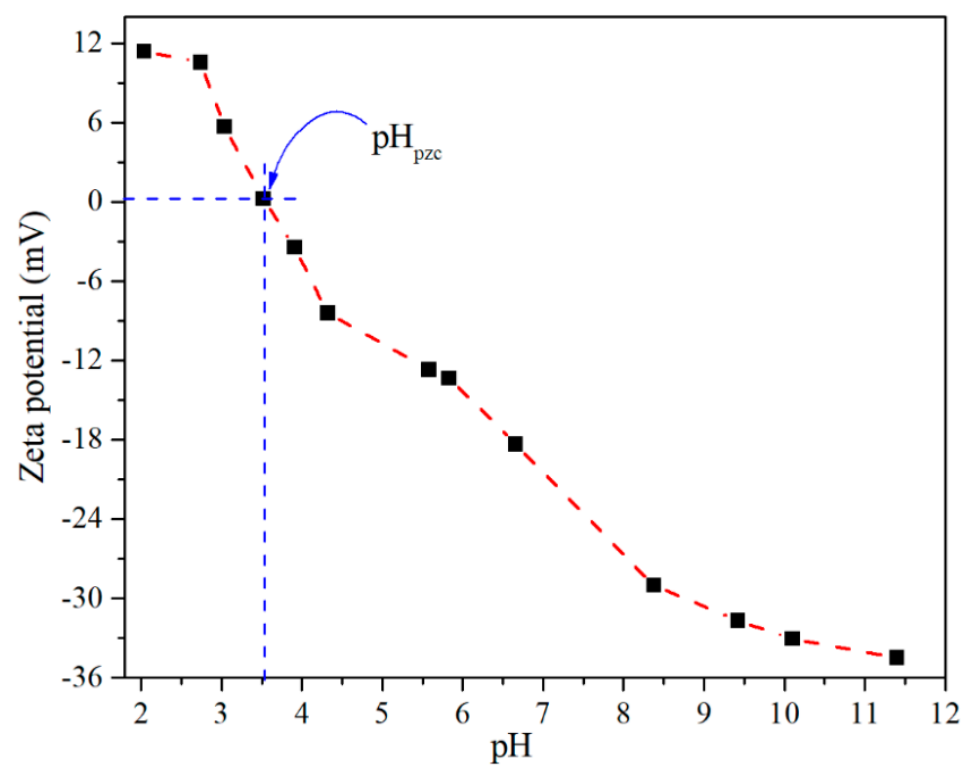

Figure 5. Zeta potential of $\mathrm{CTO}$ at $\mathrm{pH}$ between 2 and 11.

\subsection{Batch Adsorption Experiments}

Figure 6 shows the effect of $\mathrm{pH}$ on the adsorption of As(III) by CTO nanoparticles. The maximum value is obtained at $\mathrm{pH} 3$ and, as the $\mathrm{pH}$ increases, the adsorption decreases until $\mathrm{pH} 7$ where it reaches a plateau of constant adsorption. These results are similar to those obtained by Liu et al. [21] for Fe-Mn-Ce ternary oxide-biochar composites. In the range between $\mathrm{pH} 4$ and $\mathrm{pH} 5$ there is also a slight plateau, whereas at $\mathrm{pH}$ below 3 the adsorption tends to decrease. From the Pourbaix diagram, at low $\mathrm{pH}$, neutral species $\left(\mathrm{H}_{3} \mathrm{AsO}_{3}\right)$ predominate while over $\mathrm{pH} 7$ approximately equimolar mixtures of $\left(\mathrm{H}_{3} \mathrm{AsO}_{3}\right)$ and $\left(\mathrm{H}_{2} \mathrm{AsO}_{3}\right)^{-}$are present [33]. The decrease of the $\mathrm{As}(\mathrm{III})$ adsorption at pH 7 suggests that an electrostatic factor predominates due to repulsion between the negatively charge CTO surface and the oxoanion $\mathrm{AsO}(\mathrm{OH})^{2-}$. This would lead to the formation of surface complexes according to Duta et al. [33] which saturate the adsorption surface.

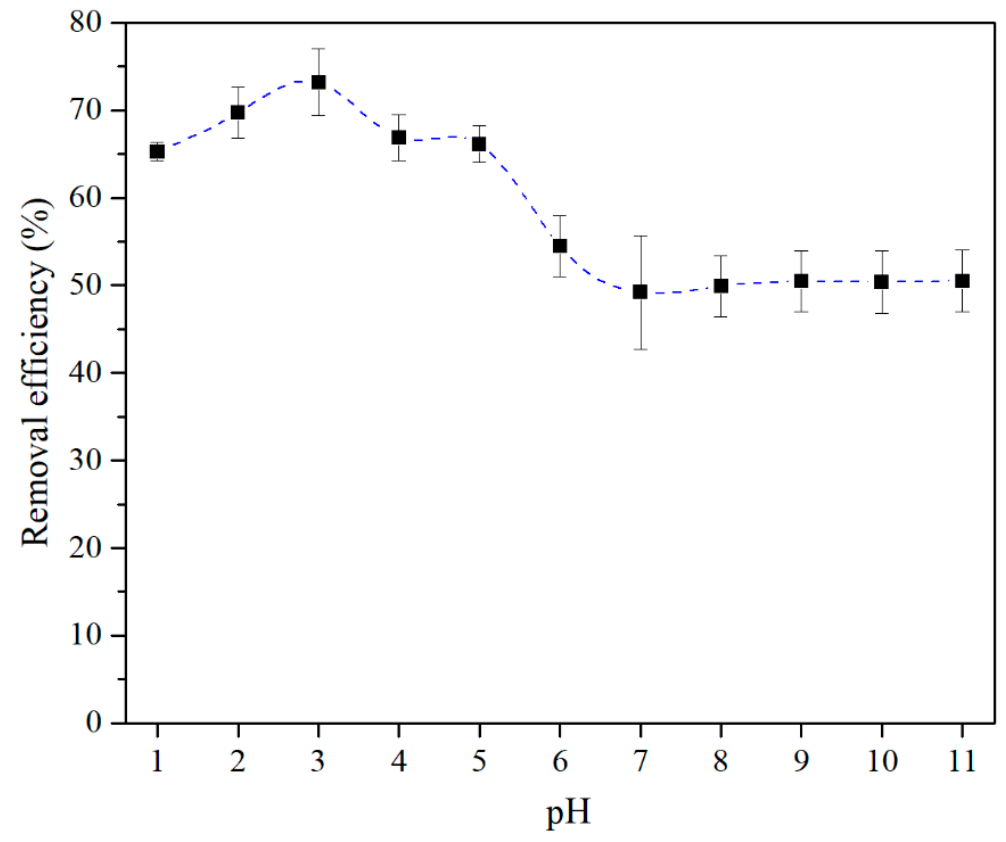

Figure 6. Effect of $\mathrm{pH}$ on $\mathrm{As}(\mathrm{III})$ adsorption by $\mathrm{CTO}$ nanoparticles. 
In contrast, below $\mathrm{pH}$, it seems that the electrostatic ion-exchange interaction (or outer-sphere) would not explain the maximum adsorption at $\mathrm{pH} 3$, at which the $\mathrm{CTO}$ surface becomes positive but the predominant species is neutral. Thus, the behavior at the low $\mathrm{pH}$ range is more likely to be related to the inner-sphere surface complex formation, i.e., As(III)-O-Ti(CTO) bonding. Wei et al. [34] proposed a microcosmic process mainly between arsenic and the surface, i.e., concerning the surface cations with positive charge which would attract the $\mathrm{O}$ atom of the arsenic species and the surface $\mathrm{O}$ with negative charge would attract the $\mathrm{H}$ atom of the arsenic species. This process is coherent with the fact that the maximum is near the IEP, while below $\mathrm{pH} 3$, the adsorption is reduced by the high concentration of protons. The protons present in the acid solution would occupy the oxygen sites on the CTO surface, thus reducing the active sites for the adsorption of the neutral oxianion $\left(\mathrm{H}_{3} \mathrm{AsO}_{3}\right)$ near $\mathrm{pH} 1$.

CTO is a very stable material and virtually insoluble at room temperature and neutral $\mathrm{pH}$ [35], which can also be extended to alkaline media [36]. On the other hand, in acid media, thermodynamic considerations indicate that CTO could suffer calcium leaching from the outermost layers of the particles [36]. XRF measurements to aliquots obtained at different times from batch experiments under acidic conditions, demonstrated that a residual amount of $\mathrm{Ca}$ and Ti are present, as is shown in the plot of Figure 7. The quantities detected do not show a correlation with the adsorption time and can be considered nearly constant. This is not consistent with a dissolution process and, on the contrary, would be attributed to residual nanoparticles that were not effectively separated during the centrifugation of the aliquots, given that the quantities detected for both elements follow the same tendency for the three $\mathrm{pH}$ conditions.

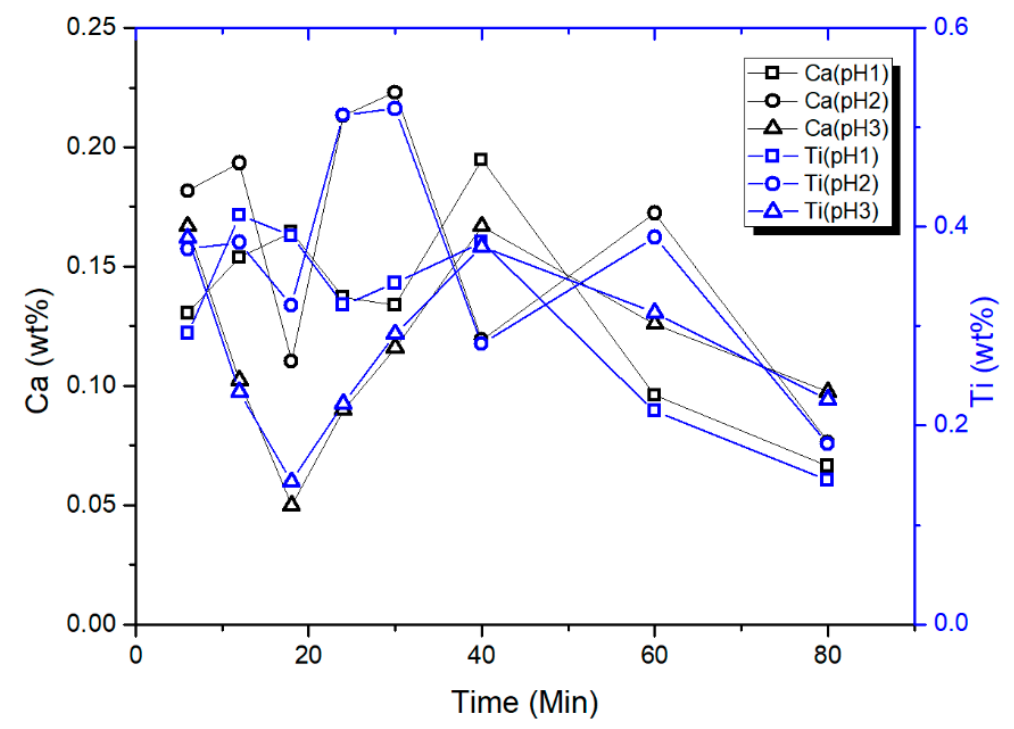

Figure 7. Ca (left axis) and Ti (right axis) content from aliquots obtained at different times in batch experiments, at $\mathrm{pH} 1,2$, and 3 .

XRD analysis performed on the CTO powders after the adsorption experiments Figure 8, showed no degradation of the crystalline structure after exposition to a wide $\mathrm{pH}$ range. This indicates the chemical stability of CTO nanopowders under acidic and basic conditions and confirms the results discussed above. 


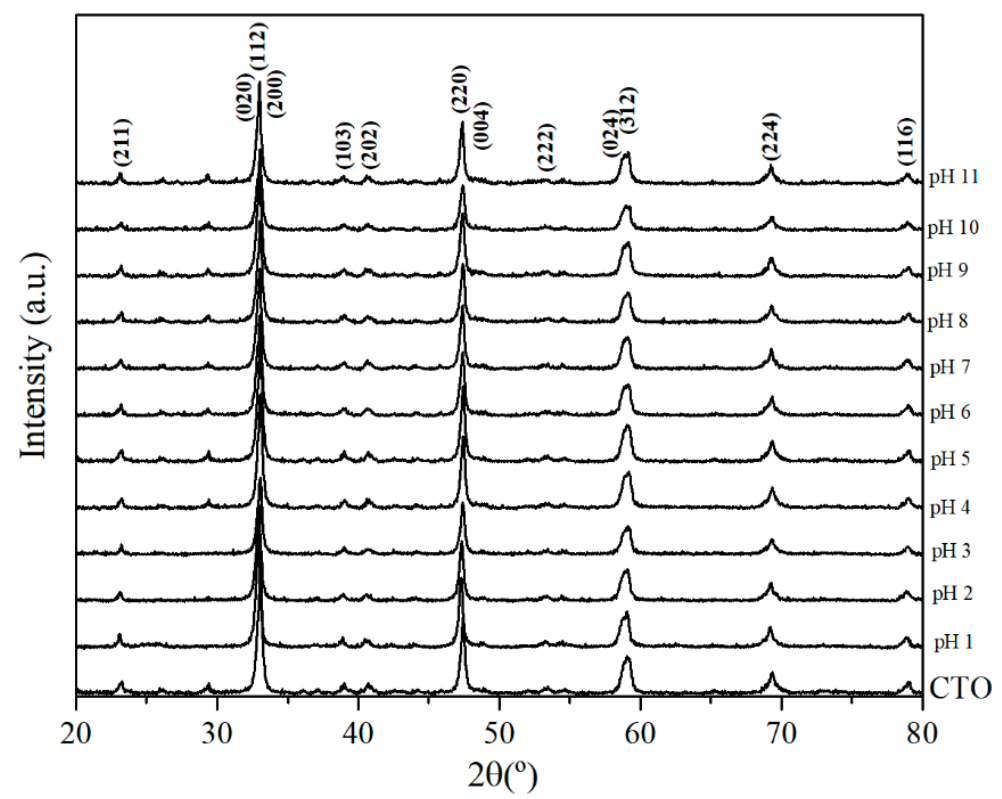

Figure 8. XRD patterns of CTO nanoparticles after removal of As(III) in acidic and basic conditions.

Time dependent plots of the adsorption behavior of CTO nanoparticles, measured at different $\mathrm{pHs}$, are shown in Figure 9. The highest As(III) adsorption is reached at $\mathrm{pH} 3$ compared to those at $\mathrm{pH} 1,4$, and 7. These results are coherent with those obtained at different $\mathrm{pHs}$ (Figure 6).

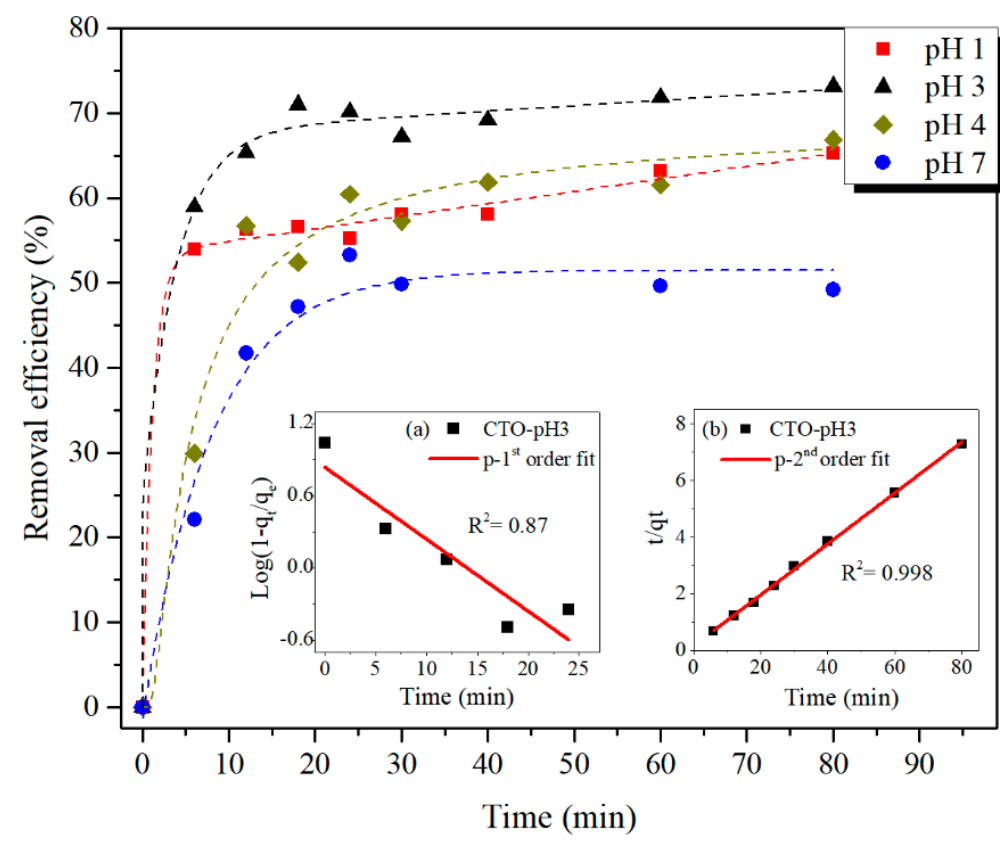

Figure 9. Time dependent adsorption behavior of As(III) by CTO nanoparticles at different $\mathrm{pHs}$. For the sake of clarity, the curves of $\mathrm{pH} 2$ and 5 are not included. Inset: Linear fit of the kinetic adsorption at $\mathrm{pH} 3$ by (a) pseudo-first and (b) pseudo-second order models.

The adsorption curves of As(III) were analyzed using kinetic models of pseudo-first (Equation (1)) and pseudo-second (Equation (2)) order proposed by Lagergren, commonly considered for adsorption studies [37]:

$$
\frac{d q_{t}}{d t}=k_{1}\left(q_{e}-q_{t}\right)
$$




$$
\frac{d q_{t}}{d t}=k_{2}\left(q_{e}-q_{t}\right)^{2}
$$

where $q_{e}$ is the adsorption capacity at equilibrium, $q_{t}$ is the removal capacity as function of time $t, k_{1}$ and $k_{2}$ are constants of velocity of pseudo-first and pseudo-second order, respectively. The linear form of these kinetic models is expressed in Equations (3) and (4) after integrating Equations (1) and (2), respectively.

$$
\begin{gathered}
\log \frac{\left(q_{e}-q_{t}\right)}{q_{e}}=-\frac{k_{1}}{2.303} t \\
\frac{t}{q_{t}}=\frac{1}{k_{2} q_{e}^{2}}+\frac{t}{q_{e}}
\end{gathered}
$$

As an example, the insets of Figure 9 depict the fits of kinetic adsorption results at $\mathrm{pH} 3$, using both models. It can be clearly seen, best fitting is obtained with the pseudo-second order model, that renders a goodness of the fit parameter $\left(R^{2}\right)$ of 0.998 , higher than the $R^{2}$ of the pseudo-first order model $\left(R^{2}=0.87\right)$.

The values of $k_{2}, q_{e}$, and $\mathrm{R}^{2}$ of the pseudo-second order model for the different $\mathrm{pHs}$ are listed in Table 1 . It can be verified that the highest velocity and adsorption capacity is obtained by carrying out the As adsorption at $\mathrm{pH} 3$.

Table 1. Calculated parameters from the second order kinetic model of the arsenic removal kinetics with $\mathrm{CTO}$, in function of $\mathrm{pH}$.

\begin{tabular}{cccc}
\hline $\begin{array}{c}\text { Pseudo-Second Order Kinetic } \\
\text { Parameters }\end{array}$ & $\begin{array}{c}\boldsymbol{k}_{\mathbf{2}} \\
{\left[\mathbf{g ~ m g}^{\mathbf{- 1}} \mathbf{~ m i n}^{\mathbf{- 1}} \mathbf{]}\right.}\end{array}$ & $\begin{array}{c}\boldsymbol{q}_{e} \\
{\left[\mathbf{m g ~ g}^{\mathbf{- 1}} \mathbf{]}\right.}\end{array}$ & $\mathbf{R}^{\mathbf{2}}$ \\
\hline pH 1 & 0.0296 & 10.00 & 0.996 \\
pH 2 & 0.0374 & 10.43 & 0.994 \\
pH 3 & 0.0508 & 11.12 & 0.999 \\
pH 4 & 0.0406 & 9.65 & 0.996 \\
pH 5 & 0.0211 & 8.37 & 0.975 \\
pH 7 & 0.0250 & 8.89 & 0.974 \\
\hline
\end{tabular}

For similar As adsorption experiments, higher $k_{2}$ values with different absorbent materials have been reported. $\mathrm{Li}$ et al. [38] studied the adsorption mechanism of $\mathrm{TiO}_{2}$-anatase that exhibited a $k_{2}$ of $0.244\left(\mathrm{mg} \mathrm{g}^{-1} \mathrm{~min}^{-1}\right)$, while the $q_{e}$ (adsorption capacity in equilibrium) was of $2.639\left(\mathrm{mg} \mathrm{g}^{-1}\right)$. Similar results were shown by Pena et al. [39] for $\mathrm{TiO}_{2}$ nanocrystals in the adsorption of $\mathrm{As}(\mathrm{V}$ and III) and, by Li et al. [20] who studied the adsorption of As by mesoporous activated carbon. In this last case, the kinetic model showed constants of $k_{2}=0.1866\left(\mathrm{~g} \mathrm{mg}^{-1} \mathrm{~min}^{-1}\right)$ and $q_{e}=0.425\left(\mathrm{mg} \mathrm{g}^{-1}\right)$. On the other hand, smaller $k_{2}$ values, below $0.01 \mathrm{mg} \mathrm{g}^{-1} \mathrm{~min}^{-1}$, were shown by Yang et al. [40] in the adsorption of As(III) by $\mathrm{ZnO}$ microtubes; and also in adsorption experiments at similar initial concentrations of $\mathrm{Mn} @ \mathrm{FeO}_{\mathrm{x}}$ composites [41]. It is worth noting that for all of these cases, the results of this study with CTO showed higher $q_{e}$ even at $\mathrm{pH} 7$.

\subsection{Effect of Coexisting Anions}

The influence of co-existing anions on arsenic adsorption was analyzed considering different amounts of chloride $\left(\mathrm{Cl}^{-}\right)$, sulfates $\left(\mathrm{SO}_{4}^{2-}\right)$, and carbonates $\left(\mathrm{CO}_{3}^{2-}\right)$ and nitrates $\left(\mathrm{NO}_{3}^{-}\right)$. Figure 10 shows that an increase in the ions' concentration leads to a decrease in the removal efficiency of As for all the coexisting elements. The stronger effect is observed for $\left(\mathrm{CO}_{3}^{2-}\right)$ that reaches a removal loss of up to $12.8 \%$ at its highest concentration $\left(500 \mathrm{mg} \mathrm{L}^{-1}\right)$, while the smaller influence is for $\left(\mathrm{Cl}^{-}\right)$. This can be attributed to the higher negative charge of carbonates in comparison to the other ions, which could form complexes on the CTO surface that competes with As adsorption. 


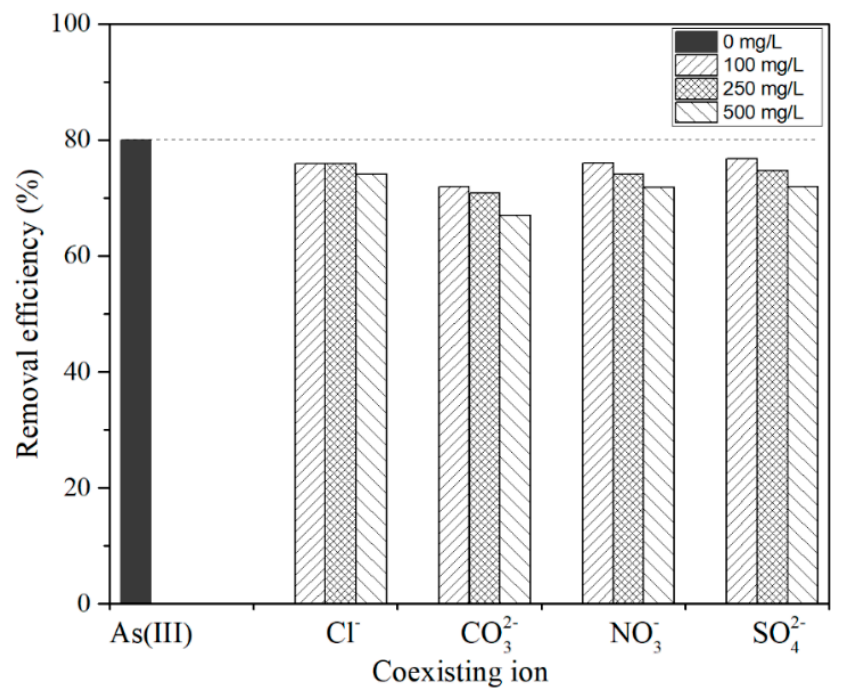

Figure 10. Effect of co-existing anions on $\mathrm{As}(\mathrm{III})$ removal by CTO nanoparticles (initial concentration $15 \mathrm{mg} \mathrm{L}^{-1}$, dose $1 \mathrm{~g} \mathrm{~L}^{-1}$, shaking $300 \mathrm{rpm}$ for $2 \mathrm{~h}$ at room temperature and $\mathrm{pH} 3$ ).

$\mathrm{Su}$ et al. [42] studied the removal of arsenic with porous $\mathrm{Fe}_{2} \mathrm{O}_{3}-\mathrm{TiO}_{2}$ ceramics. They also evaluated the effect on the arsenic removal of different ions phosphates, sulfates, and carbonates with concentrations between 10 to $50 \mathrm{mg} \mathrm{L}^{-1}$. They reported that carbonates reduce the removal of arsenic up to $50 \%$ with the highest concentration $\left(50 \mathrm{mg} \mathrm{L}^{-1}\right)$. In the present study, we used 10 times this concentration and a reduction four times smaller was obtained. Similarly, Thanawatpoontawee et al. [24] carried out a study on zein beads loaded with iron as a biocompatible adsorbent for the elimination of arsenic. They also evaluated the effect of common ions on arsenic removal using $100 \mathrm{mg}$ $\mathrm{L}^{-1}$ as the maximum concentration. In their case, the ions that most affected arsenic removal were $\left(\mathrm{SO}_{4}^{2-}\right)$ and $\left(\mathrm{PO}_{4}^{3-}\right)$, decreasing by up to $50 \%$ and $80 \%$ respectively at the maximum concentration.

\subsection{Recycle and Stability}

The recyclability or regeneration of the adsorbent material (CTO) is an important factor to minimize the treatment costs, so that the same adsorbent can be reused several times. To evaluate the recyclability of the CTO, four consecutive adsorption and desorption cycles were tested. The results are presented in Figure 11, where the adsorption results decrease to $12 \%$ in the fourth cycle and in the case of desorption, down to $17 \%$ for arsenic removal from water. Min Deg et al. [43], studied $\mathrm{TiO}_{2}$ nanoparticles anchored on nanosheets of $\mathrm{Fe}_{3} \mathrm{O}_{4}$ for the removal of arsenic. Their evaluation of regeneration exhibited a $30 \%$ drop of the arsenic removal, from the third regeneration cycle the removal of arsenic drops by $30 \%$. The structural stability of the CTO analyzed by XRD at the end of each cycle showed that the nanoparticles were not altered by the chemical reactions during desorption-absorption cycles Figure 12. 


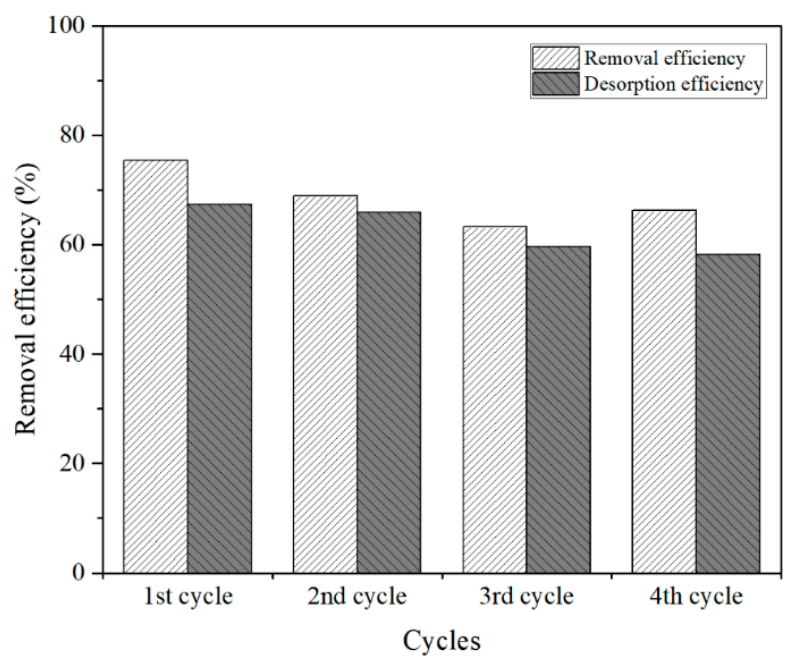

Figure 11. Regeneration studies of adsorption and desorption of As(III).

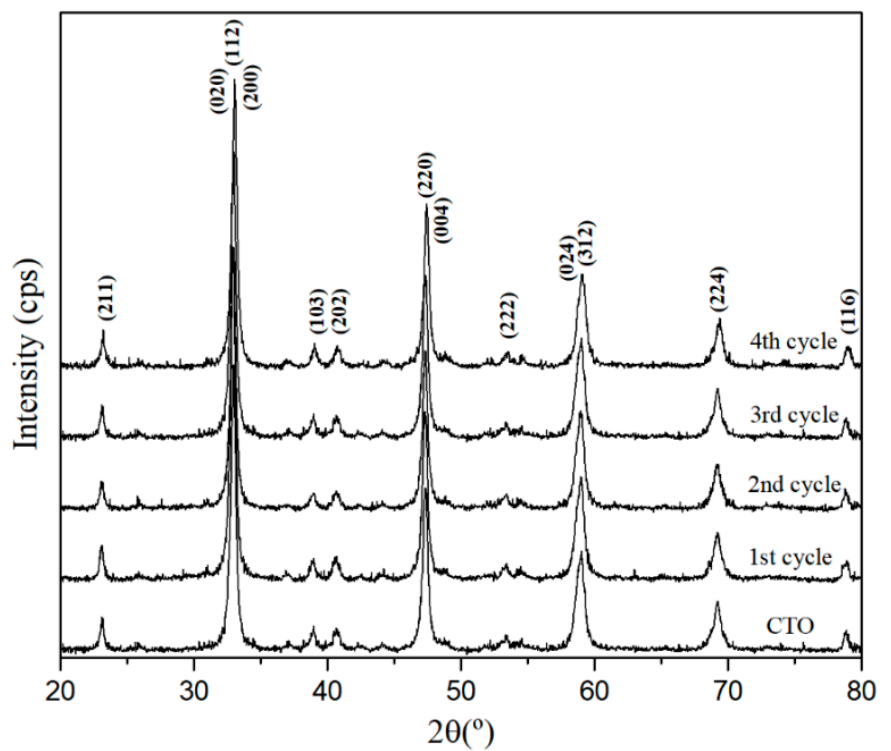

Figure 12. XRD pattern of CTO nanoparticles measured after each cycle of regeneration.

\subsection{Characterization of CTO Surface after Adsorption Experiments}

The surface of the CTO nanoparticles was analyzed by XPS after adsorption experiments to study the presence of As and its oxidation states. The samples analyzed were CTO powders before adsorption experiments, and those after adsorption kinetics at pH 3 and pH 7, CTO-pH3 and CTO-pH7, respectively. Figure 13 depicts the three spectra that show As presence in samples of $\mathrm{pH} 3$ and $\mathrm{pH} 7$, and the other expected signals of $\mathrm{Ca}, \mathrm{Ti}, \mathrm{O}$, and $\mathrm{C}[44,45]$.

To elucidate the states of the different species after adsorption, high-resolution XPS spectra (HRXPS) were also obtained. The HRXPS of Ti2p and Ca2p (not included here) does not show any change on the incorporation of As on the CTO surface. On the other hand, the O1s signal in CTO after As adsorption, Figure 14a,b, exhibited two contributions from the different oxygen species: at $531.6 \mathrm{eV}$ binding energy (O-As), and $529.8 \mathrm{eV}$ of binding energy $(\mathrm{O}=\mathrm{As})$. A binding energy shift of these oxygen species is observed, which can be explained by the CTO presence and the $\mathrm{O}=\mathrm{As}-\mathrm{O}$ formation from the arsenite removal. 


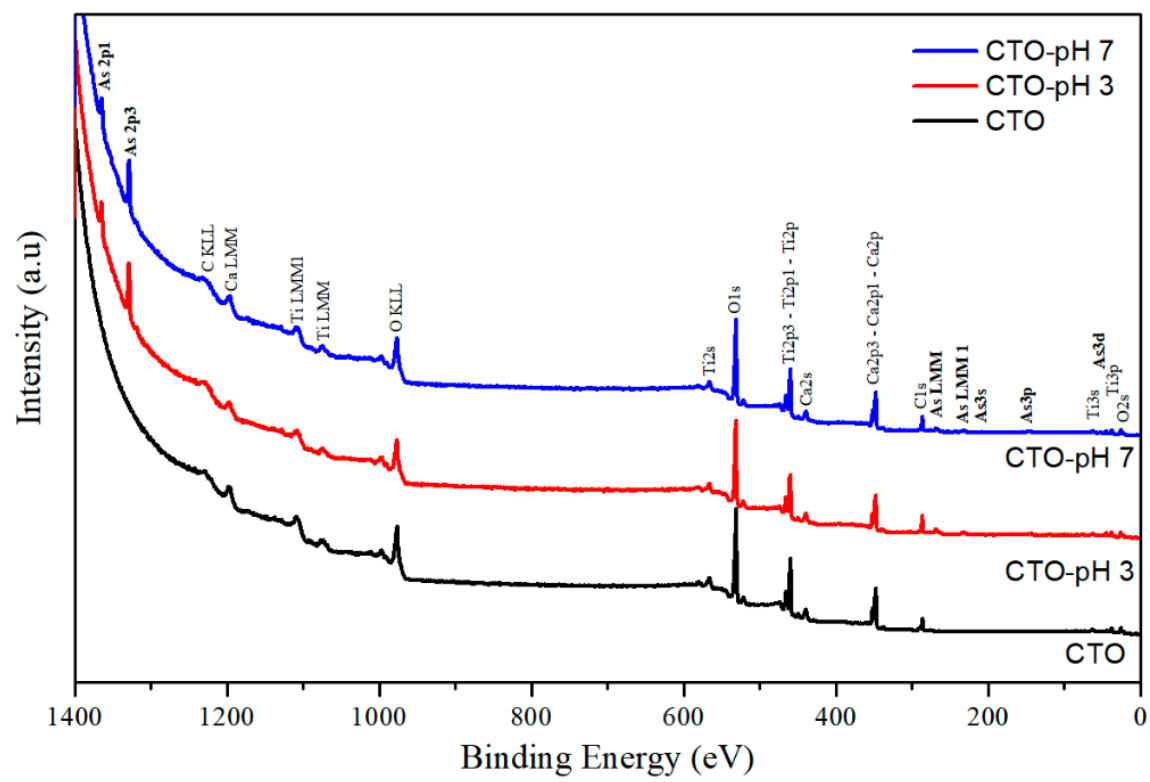

Figure 13. XPS survey spectra of samples before and after adsorption experiments at pH 3 and 7.
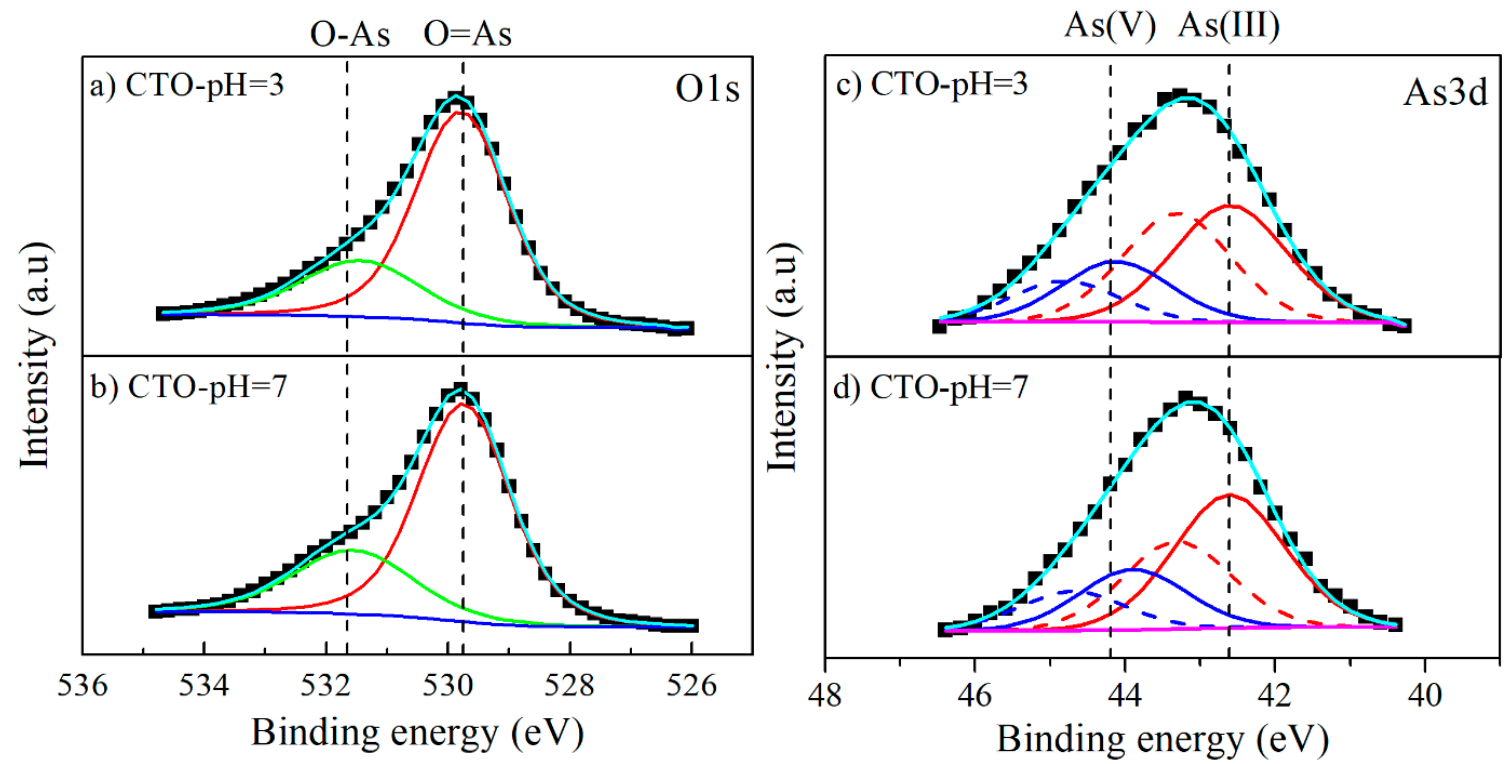

Figure 14. High-resolution XPS spectra of CTO after adsorption experiments at pH 3 and 7.

For the As 3d signal, the fit was performed considering the As3d5/2 and As3d3/2 doublets, separated by $0.69 \mathrm{eV}$ and area ratio of 5/3 [46], and taking into account an energy separation between both signals of $1.4 \mathrm{eV}[47,48]$. After adsorption experiments, the CTO-pH3 sample exhibited two doublets at 42.6 and $44.1 \mathrm{eV}$ (Figure 14c), identified as $\mathrm{As}(\mathrm{III})$ and $\mathrm{As}(\mathrm{V})$, respectively [46-48]. Sample CTO-pH7 showed similar results (Figure 14d) but a shift of the $\mathrm{As}(\mathrm{V})$ binding energy to $43.9 \mathrm{eV}$, Nevertheless, the ratio between $\mathrm{As}(\mathrm{III})$ and $\mathrm{As}(\mathrm{V})$ signals does not change by the $\mathrm{pH}$ increase in the solutions. Thus, XPS results indicate that As is adsorbed on the surface of CTO nanoparticles as As(III) and is partially oxidized to As(V). Similar behavior was observed by Jegadeesan et al. [49] for As sorption on $\mathrm{TiO}_{2}$ nanoparticles, which could be attributed to the presence of surface hydroxyl groups or physiosorbed oxygen. 


\section{Conclusions}

The CTO nanoparticles prepared by the sol-gel technique were demonstrated to be a good adsorbent of As(III) with a maximum adsorption capacity of $11.12 \mathrm{mg} \mathrm{g}^{-1}$ at room temperature, which is higher than other values reported in similar studies. It was shown that the adsorption capacity of As varies with the $\mathrm{pH}$ of the solution, and that the maximum adsorption capacity was given at $\mathrm{pH} 3$ which coincides with the isoelectric point of the CTO nanoparticles. This is related to an inner-sphere surface complex formation of As(III)-O-Ti(CTO) bonding. The study on adsorption kinetics shows that this system follows a pseudo-second order model. The X-ray photoelectron spectroscopy analysis of the CTO surface after removal experiments, showed that arsenic was present as As(III) and partially oxidized to $\mathrm{As}(\mathrm{V})$. Under these conditions of removal, the addition of interfering ions $\left(\mathrm{CO}_{3}^{2-}, \mathrm{NO}_{3}^{-}\right.$, $\mathrm{SO}_{4}^{2-}$ and $\mathrm{Cl}^{-}$) did not cause a significant decrease of As(III) adsorption using CTO. Additionally, the regeneration of the CTO is possible and confirms that the adsorption is reversible.

Author Contributions: R.T. and R.E.-G. conceived and designed the experiments; R.T. performed the synthesis and characterization by XRD, Z potential, adsorption, and batch experiments. R.E.-G. performed the TEM characterization, project management, data analysis, and manuscript writing. F.G. analyzed the data and supported the manuscript writing. U.P.R.-F. supported the adsorption experiments and their data analysis. M.F. performed the XPS characterization and analysis. E.S. performed XRD characterization and support in the adsorption experiments at different $\mathrm{pHs}$, desorption, and coexisting ions.

Funding: This research was funded by CONICYT-Chile, grant number FONDECYT Regular 1150652 (R.E.-G.) and 1171193 (F.G.). Authors F.G. and R.E.-G. also acknowledge the support of MINECON-Chile through project Millennium Nucleus MULTIMAT-ICM/MINECON. R. Tamayo-Calderon would like to thank the scholarship support $\mathrm{N}^{\circ}$ 078-FINCYT-BDE-2014 (FINCyT/INNOVATE, Perú), and also to Prof. Lorena Cornejo (Universidad de Tarapacá) for her support in the experimental set up.

Conflicts of Interest: The authors declare no conflict of interest.

\section{References}

1. Mohan, D.; Pittman, C.U. Arsenic removal from water/wastewater using adsorbents-A critical review. J. Hazard. Mater. 2007, 142, 1-53. [CrossRef] [PubMed]

2. Roy, P.K.; Majumder, A.; Banerjee, G.; Roy, M.B.; Pal, S.; Mazumdar, A. Removal of arsenic from drinking water using dual treatment process. Clean Technol. Environ. Policy 2015, 17, 1065-1076. [CrossRef]

3. German, M.; Seingheng, H.; SenGupta, A.K. Mitigating arsenic crisis in the developing world: Role of robust, reusable and selective hybrid anion exchanger (HAIX). Sci. Total Environ. 2014, 488-489, 547-553. [CrossRef] [PubMed]

4. World Health Organization (WHO). Arsenic in Drinking-Water: Background Document for Development of WHO Guidelines for Drinking-Water Quality; WHO: Geneva, Switzerland, 2011.

5. Bundschuh, J.; Litter, M.I.; Parvez, F.; Román-Ross, G.; Nicolli, H.B.; Jean, J.S.; Liu, C.W.; López, D.; Armienta, M.A.; Guilherme, L.R.G.; et al. One century of arsenic exposure in Latin America: A review of history and occurrence from 14 countries. Sci. Total Environ. 2012, 429, 2-35. [CrossRef]

6. Byrne, S.; Amarasiriwardena, D.; Bandak, B.; Bartkus, L.; Kane, J.; Jones, J.; Yañez, J.; Arriaza, B.; Cornejo, L. Were Chinchorros exposed to arsenic? Arsenic determination in Chinchorro mummies' hair by laser ablation inductively coupled plasma-mass spectrometry (LA-ICP-MS). Microchem. J. 2010, 94, 28-35.

7. Mandal, B.; Suzuki, K. Arsenic round the world: A review. Talanta 2002, 58, 201-235. [CrossRef]

8. Cullen, K.R.; Reimer, K.J. Arsenic speciation in the environment. Chem. Rev. 1989, 89, 713-764. [CrossRef]

9. Corkhill, C.L.; Vaughan, D.J. Arsenopyrite oxidation-A review. Appl. Geochem. 2009, 24, $2342-2361$. [CrossRef]

10. Bissen, M.; Frimmel, F.H.; Ag, C. Arsenic-A Review. Part I: Occurrence, Toxicity, Speciation, Mobility. Acta Hydrochim. Hydrobiol. 2003, 31, 9-18. [CrossRef]

11. Pourbaix, M. Atlas of Chemical and Electrochemical Equilibria in the Presence of a Gaseous Phase; National Assn of Corrosion: Houston, TX, USA, 1997; ISBN 9782960013405.

12. Manning, B. Surface Structures and Stability of Arsenic(III) on Goethite: Spectroscopic Evidence for Inner-Sphere Complexes. Environ. Sci. Technol. 1998, 32, 2383-2388. [CrossRef] 
13. Jain, A.; Raven, K.P.; Loeppert, R.H. Arsenite and Arsenate adsorption on ferrihydrite: Surface charge reduction and net $\mathrm{OH}-$ release stoichiometry. Environ. Sci. Technol. 1999, 33, 1179-1184. [CrossRef]

14. Hu, C.; Liu, H.; Chen, G.; Qu, J. Effect of aluminum speciation on arsenic removal during coagulation process. Sep. Purif. Technol. 2012, 86, 35-40. [CrossRef]

15. Lacasa, E.; Cañizares, P.; Sáez, C.; Fernández, F.J.; Rodrigo, M.A. Removal of arsenic by iron and aluminium electrochemically assisted coagulation. Sep. Purif. Technol. 2011, 79, 15-19. [CrossRef]

16. Mohora, E.; Rončević, S.; Agbaba, J.; Tubić, A.; Mitić, M.; Klašnja, M.; Dalmacija, B. Removal of arsenic from groundwater rich in natural organic matter (NOM) by continuous electrocoagulation/flocculation (ECF). Sep. Purif. Technol. 2014, 136, 150-156. [CrossRef]

17. Zavareh, S.; Zarei, M.; Darvishi, F.; Azizi, H. As(III) adsorption and antimicrobial properties of $\mathrm{Cu}$-chitosan/alumina nanocomposite. Chem. Eng. J. 2015, 273, 610-621. [CrossRef]

18. Hlavay, J.; Polyák, K. Determination of surface properties of iron hydroxide-coated alumina adsorbent prepared for removal of arsenic from drinking water. J. Colloid Interface Sci. 2005, 284, 71-77. [CrossRef]

19. Vitela-Rodriguez, A.V.; Rangel-mendez, J.R. Arsenic removal by modified activated carbons with iron hydro (oxide) nanoparticles. J. Environ. Manag. 2013, 114, 225-231. [CrossRef] [PubMed]

20. Li, W.-G.; Gong, X.-J.; Wang, K.; Zhang, X.-R.; Fan, W.-B. Adsorption characteristics of arsenic from micro-polluted water by an innovative coal-based mesoporous activated carbon. Bioresour. Technol. 2014, 165, 166-173. [CrossRef]

21. Liu, X.; Zhang, G.; Lin, L.; Khan, Z.; Qiu, W.; Song, Z. Synthesis and Characterization of Novel Fe-Mn-Ce Ternary Oxide-Biochar Composites as Highly Efficient Adsorbents for As (III) Removal from Aqueous Solutions. Materials 2018, 11, 2445. [CrossRef] [PubMed]

22. Chowdhury, T.; Zhang, L.; Zhang, J.; Aggarwal, S. Removal of Arsenic(III) from Aqueous Solution Using Metal Organic Framework-Graphene Oxide Nanocomposite. Nanomaterials 2018, 8, 1062. [CrossRef] [PubMed]

23. Cornejo, L.; Lienqueo, H.; Arenas, M.; Acarapi, J.; Contreras, D.; Yáñez, J.; Mansilla, H.D. In field arsenic removal from natural water by zero-valent iron assisted by solar radiation. Environ. Pollut. 2008, 156, 827-831. [CrossRef]

24. Thanawatpoontawee, S.; Imyim, A.; Praphairaksit, N. Iron-loaded zein beads as a biocompatible adsorbent for arsenic(V) removal. J. Ind. Eng. Chem. 2016, 43, 127-132. [CrossRef]

25. Xu, X.; Tang, Y.; Mo, F.; Zhou, L.; Li, B. Synthesis and luminescent properties of $\mathrm{CaTiO}_{3}: \mathrm{Eu}^{3+}, \mathrm{Al}^{3+}$ phosphors. Ceram. Int. 2014, 40, 10887-10892. [CrossRef]

26. Oliveira, L.H.; De Moura, A.P.; La Porta, F.A.; Nogueira, I.C.; Aguiar, E.C.; Sequinel, T.; Rosa, I.L.V.; Longo, E.; Varela, J.A. Influence of Cu-doping on the structural and optical properties of $\mathrm{CaTiO}_{3}$ powders. Mater. Res. Bull. 2016, 81, 1-9.

27. Manik, S.K.; Pradhan, S.K.; Pal, M. Nanocrystalline $\mathrm{CaTiO}_{3}$ prepared by soft-chemical route. Physica E 2005, 25, 421-424. [CrossRef]

28. Yang, X.; Wang, X.; Huang, M.; Zhang, S.; Li, L. Synthesis and characterization of $\mathrm{CaTiO}_{3}-(\mathrm{Sm}, \mathrm{Nd}) \mathrm{AlO}_{3}$ microwave ceramics via sol-gel method. J. Sol-Gel Sci. Technol. 2014, 69, 61-66. [CrossRef]

29. Du, Q.; Zhou, G.; Zhou, J.; Zhou, H.; Zhan, J.; Yang, Z. Facile sol-gel combustion synthesis and photoluminescence enhancement of $\mathrm{CaZrO}_{3}: \mathrm{Sm}^{3+}$ nanophosphors via Gd ${ }^{3+}$ doping. J. Rare Earths 2012, 30, 1000-1004. [CrossRef]

30. Jia, C.; Gao, J.; Li, J.; Gu, F.; Xu, G.; Zhong, Z.; Su, F. Nickel catalysts supported on calcium titanate for enhanced CO methanation. Catal. Sci. Technol. 2013, 3, 490-499. [CrossRef]

31. Zhuang, J.; Tian, Q.; Lin, S.; Yang, W.; Chen, L.; Liu, P. Applied Catalysis B: Environmental Precursor morphology-controlled formation of perovskites $\mathrm{CaTiO}_{3}$ and their photo-activity for As(III) removal. Appl. Catal. B Environ. 2014, 156-157, 108-115. [CrossRef]

32. Coreño, J.; Coreño, O. Evaluation of calcium titanate as apatite growth promoter. J. Biomed. Mater. Res. Part A 2005, 75, 478-484. [CrossRef] [PubMed]

33. Dutta, P.K.; Ray, A.K.; Sharma, V.K.; Millero, F.J. Adsorption of arsenate and arsenite on titanium dioxide suspensions. J. Colloid Interface Sci. 2004, 278, 270-275. [CrossRef]

34. Wei, Z.; Liang, K.; Wu, Y.; Zou, Y.; Zuo, J.; Arriagada, D.C.; Pan, Z.; Hu, G. The effect of pH on the adsorption of arsenic(III) and arsenic(V) at the $\mathrm{TiO}_{2}$ anatase [101] surface. J. Colloid Interface Sci. 2016, 462, 252-259. [CrossRef] 
35. Nesbitt, H.W.; Bancroft, G.M.; Fyfe, W.S.; Karkhanis, S.N.; Nishijima, A.; Shin, S. Thermodynamic stability and kinetics of perovskite dissolution. Nature 1981, 289, 358-362. [CrossRef]

36. Blesa, M.A.; Morando, P.J.; Regazzoni, A.E. Chemical Dissolution of Metal Oxides, 1st ed.; Taylor \& Francis Group: Boca Raton, FL, USA, 1994; Chapter 17.

37. Ho, Y.S.; McKay, G. A Comparison of Chemisorption Kinetic Models Applied to Pollutant Removal on Various Sorbents. Process Saf. Environ. Prot. 1998, 76, 332-340. [CrossRef]

38. Li, Y.; Cai, X.; Guo, J.; Na, P. UV-induced photoactive adsorption mechanism of arsenite by anatase $\mathrm{TiO}_{2}$ with high surface hydroxyl group density. Colloids Surf. A Physicochem. Eng. Asp. 2014, 462, 202-210. [CrossRef]

39. Pena, M.E.; Korfiatis, G.P.; Patel, M.; Lippincott, L.; Meng, X. Adsorption of As(V) and As(III) by nanocrystalline titanium dioxide. Water Res. 2005, 39, 2327-2337. [CrossRef] [PubMed]

40. Yang, W.; Li, Q.; Gao, S.; Shang, J.K. High efficient As(III) removal by self-assembled zinc oxide micro-tubes synthesized by a simple precipitation process. J. Mater. Sci. 2011, 46, 5851-5858. [CrossRef]

41. Cho, D.-W.; Chon, C.-M.; Yang, H.; Tsang, Y.F.; Song, H. Effect of Mn substitution on the oxidation/adsorption abilities of iron(III) oxyhydroxides. Clean Technol. Environ. Policy 2018, 20, 2201-2208. [CrossRef]

42. Su, H.; Lv, X.; Zhang, Z.; Yu, J.; Wang, T. Arsenic removal from water by photocatalytic functional $\mathrm{Fe}_{2} \mathrm{O}_{3}-\mathrm{TiO}_{2}$ porous ceramic. J. Porous Mater. 2017, 24, 1227-1235. [CrossRef]

43. Deng, M.; Wu, X.; Zhu, A.; Zhang, Q.; Liu, Q. Well-dispersed $\mathrm{TiO}_{2}$ nanoparticles anchored on $\mathrm{Fe}_{3} \mathrm{O}_{4}$ magnetic nanosheets for efficient arsenic removal. J. Environ. Manag. 2019, 237, 63-74. [CrossRef] [PubMed]

44. Han, C.; Liu, J.; Yang, W.; Wu, Q.; Yang, H.; Xue, X. Enhancement of photocatalytic activity of $\mathrm{CaTiO}_{3}$ through $\mathrm{HNO}_{3}$ acidification. J. Photochem. Photobiol. A Chem. 2016, 323, 1-9. [CrossRef]

45. Wang, K.; Zhao, B.; Gao, L. X-ray photoemission spectroscopy investigation of $\mathrm{CaTiO}_{3}: \mathrm{Eu}_{\text {for luminescence }}$ property: Effect of $\mathrm{Eu}^{3+}$ ion. Mater. Res. Bull. 2016, 78, 31-35. [CrossRef]

46. Yan, W.; Ramos, M.A.V.; Koel, B.E.; Zhang, W. Multi-tiered distributions of arsenic in iron nanoparticles: Observation of dual redox functionality enabled by a core-shell structure. Chem. Commun. 2010, 46, 6995. [CrossRef]

47. Wang, Y.; Duan, J.; Li, W.; Beecham, S.; Mulcahy, D. Aqueous arsenite removal by simultaneous ultraviolet photocatalytic oxidation-coagulation of titanium sulfate. J. Hazard. Mater. 2016, 303, 162-170. [CrossRef]

48. Han, Y.S.; Jeong, H.Y.; Demond, A.H.; Hayes, K.F. X-ray absorption and photoelectron spectroscopic study of the association of As(III) with nanoparticulate FeS and FeS-coated sand. Water Res. 2011, 45, 5727-5735. [CrossRef]

49. Jegadeesan, G.; Al-Abed, S.R.; Sundaram, V.; Choi, H.; Scheckel, K.G.; Dionysiou, D.D. Arsenic sorption on $\mathrm{TiO}_{2}$ nanoparticles: Size and crystallinity effects. Water Res. 2010, 44, 965-973. [CrossRef] 